\title{
The Isolation and Cultivation of Sulphate-Reducing Bacteria
}

\author{
By K. R. BUTLIN, MARY E. ADAMS AND MARGARET THOMAS \\ Chemical Research Laboratory, Department of Scientific and \\ Industrial Research, Teddington, Middlesex
}

SUMMARY: There are many strains and perhaps several species of sulphate-reducing bacteria. They may be isolated by using a variety of media over a wide range of temperature. Crude cultures are readily obtained, but isolation of absolutely pure cultures is usually difficult. Considerable simplification in procedure may sometimes be effected by including $3 \% \mathrm{Na}_{2} \mathrm{SO}_{3} .7 \mathrm{H}_{2} \mathrm{O}$ in the media; the sulphite eliminates most of the contaminating organisms in crude cultures and facilitates subsequent purification. A method of maintaining stock cultures on sterile clay is preferred to the use of artificial media.

No growth takes place in media rendered 'biologically free' of iron, but the traces normally present in media constituents as impurities are sufficient for good development. Rapid and abundant growth free from ferrous sulphide has been obtained in a mineral salts + lactate + yeast extract medium containing ferrous ions below the saturation concentration for ferrous sulphide.

One thermophilic and four mesophilic strains have been shown to be facultative autotrophs, using the oxidation of hydrogen as energy source, with sulphate, sulphite, thiosulphate and elementary sulphur as hydrogen acceptors. No autotrophic growth takes place in the absence of hydrogen. Hydrogen can be provided in vitro by immersing metallic iron in the medium.

Although 'sulphate reduction is one of the most commonly occurring and extensive microbiological processes on earth' (von Wolzogen Kühr \& van der Vlugt, 1934), sulphate-reducing bacteria are physiologically unique among living organisms in being able to reduce sulphates to sulphides; Tanner's (1918) suggestion that some yeasts possess this property has not been confirmed (Bunker, 1936). They are also capable of reducing sulphites, thiosulphates and elementary sulphur to sulphides. Practically every type of soil and natural water contains them and they are widely distributed in the sea. Holland, a country of odoriferous canals and great microbiologists, contributed most to our early knowledge of them. First described by Beijerinck (1895) and isolated in pure culture by van Delden (1903), their physiology and biochemistry was comprehensively investigated by Baars (1930), while von Wolzogen $\mathrm{Kühr}$ $\&$ van der Vlugt (1934) defined their function as essential agents in the anaerobic corrosion of buried ferrous pipes. The ubiquity of the organisms led inevitably to their investigation in other countries (see Tausson \& Alioschina, 1932; Copenhagen, 1934; Bunker, 1936, 1938; Starkey, 1938; Datta, 1943; ZoBell, $1946 a, 1947)$.

Sulphate-reducers play an important part in the sulphur cycle in nature, both on land (Bunker, 1936) and in the sea (ZoBell, 1946a). Their activities, chiefly because invariably accompanied by the production of hydrogen sulphide, frequently result in undesirable manifestations, sometimes of considerable economic importance, as in the corrosion of buried metal structures or the 
contamination of coal, gas and oil. They are said to contribute to the formation of petroleum and to its modification after formation (ZoBell, 1945). A recently discovered and potentially valuable property of some strains is their power of releasing oil from oil-bearing sediments (ZoBell, 1947).

During our work on anaerobic microbiological corrosion we have been faced with the many difficulties of obtaining pure cultures of these organisms in quantities sufficient for biochemical investigation. We describe below improved methods of isolation and cultivation, demonstrate the autotrophic growth of several pure strains, and discuss related questions of nomenclature and classification.

\section{Nomenclature and classification}

The nomenclature of sulphate-reducing bacteria is confusing and their classification still uncertain. Since their first description by Beijerinck (1895) it has been generally agreed that there is only one genus, variously designated Bacillus, Bacterium, Spirillum, Microspira, Vibrio, Sporovibrio and Desulphovibrio. Kluyver \& van Niel (1936) placed them in the tribe Vibrioneae with the generic name Desulphovibrio. In Bergey's Manual, 5th edition (Bergey, 1939), they were included in the tribe Spirilleae, genus Spirillum, in an appendix containing the 'additional species (which) have been mentioned in the literature'. In the 6th edition of Bergey (1948) they are retained in the tribe Spirilleae (family Pseudomonadaceae), but are given the generic name Desulphovibrio.

The many species-names include hydrosulphureum, hydrosulphureus desulphuricans, thermodesulphuricans, with aestuarii and rubentschikii for halophilic strains. ZoBell (1947) has recently added hydrocarbonoclasticus for a species attacking petroleum hydrocarbons and halohydrocarbonoclasticus for the corresponding halophilic variety.

It may provisionally be agreed that Desulphovibrio should be the generic designation of sulphate-reducing bacteria. The question of species names is more complicated. Until 1930 it was thought there were three species, i.e. nonhalophilic, halophilic and thermophilic. Baars (1930), however, showed that these three supposed species were interconvertible by gradual acclimatization, and he regarded them as three strains of a single species, Vibrio desulphuricans. Since then many new varieties have been isolated. Bunker (unpublished observation) was unable to induce growth of some of his strains at temperatures higher than $37^{\circ}$. Rittenberg (1941) isolated obligate mesophilic and halophilic varieties from marine sediments. Sporing cultures have been described by Starkey (1938), but not all sulphate-reducers can be induced to form spores. All strains so far reported in the literature are motile, but we possess a culture isolated by Bunker in this laboratory from Thames river mud which is nonmotile and shows no flagella in electron micrographs. ZoBell (1947) described strains which attacked hydrocarbons, a property not possessed by all sulphatereducers; he also described special strains which grew at $80^{\circ}$. Although some of these differences would not in themselves justify the creation of separate species, there appears to be sufficient evidence for assuming the existence of several species. In the choice of names for new species we suggest adherence 
to Recommendation $6 b(2)$ of the International Bacteriological Code of Nomenclature, 1947 , i.e. 'to avoid those which are very long and difficult to pronounce'. We recommend that species names of more than five syllables should be avoided.

The variety of sulphate-reducing organisms has some bearing on the isolation of pure cultures. It is not sufficient to develop cultures from any given source on one medium alone. Media suitable for both non-halophiles and halophiles should be used, and, as ZoBell has shown with his hydrocarbon-attacking species, the inclusion of different carbon sources in the media may yield new varieties. The temperature of incubation is also of major importance, as shown by the existence of ZoBell's $80^{\circ}$ strains and by experiments to be described.

\section{ISOLATION OF PURE CULTURES}

It is comparatively simple to grow mixed cultures containing sulphatereducing bacteria. It is not difficult to obtain almost pure cultures, but in general it is by no means easy to isolate absolutely pure strains. Full details of the various media and methods hitherto employed may be found in papers by Beijerinck (1895), van Delden (1903), Elion (1925), Gahl \& Anderson (1928), Baars (1930), Starkey (1938) and Rittenberg (1941). Because some of these papers are not easily available and also because of the difficulties generally experienced by workers in this field, our methods are described in some detail; they include salient features of procedures adopted by other workers.

The general method used is based on that of Starkey (1938), which consists essentially in making enrichment cultures and then preparing deep agar ('shake') cultures or plates in various dilutions. A solid medium containing sulphate, lactate and a trace of ferrous salt is used; the sulphate-reducers form black colonies which can readily be picked off and placed in liquid medium. This apparently simple procedure rarely meets with immediate success except sometimes with thermophilic strains. It is difficult to obtain colonies free from contaminants, and it is frequently necessary to undertake a tedious succession of deep agar dilution cultures and platings out before pure cultures are obtained. We have found that the inclusion of $3 \% \mathrm{Na}_{2} \mathrm{SO}_{3} \cdot 7 \mathrm{H}_{2} \mathrm{O}$ in the media eliminates most of the contaminating organisms in mixed cultures and greatly facilitates subsequent purification of the sulphate-reducers.

\section{Anaerobic cultivation}

\section{Methods}

Sulphate-reducing bacteria are said to be strict anaerobes, though Bunker (1939) states that 'they can be active in very restricted areas of oxygen deficiency in close proximity to regions of abundant oxygen supply'. Some of our own experiments indicate, not conclusively, that growth may occur in the presence of 2-3 p.p.m. of oxygen. We have also grown pure strains aerobically in shallow $(1 \mathrm{~cm}$.) layers of medium to which $0.025 \%$ ascorbic acid had been added (see Kligler \& Guggenheim, 1938). Most soils incubated with medium A (below) reduce sulphate even if no anaerobic precautions are taken, presumably 
because the aerobic organisms also present deoxygenate the medium. Nevertheless, growth is much better when oxygen is rigorously excluded, and the choice of an efficient and convenient anaerobic technique is most important.

The simplest technique for crude cultures is the use of stoppered bottles completely filled with medium freed from dissolved oxygen by boiling and rapidly cooled immediately before use. This method is unsuitable for work with pure cultures owing to the ease with which contamination takes place. With normal aseptic precautions the majority of bottle cultures show significant contamination when plated aerobically on nutrient agar. Even with elaborate precautions the incidence of contamination is still too great for general work. This objection does not apply to ordinary culture tubes plugged with cottonwool soaked in alkaline pyrogallol and sealed with a rubber bung, but the method is cumbrous when large numbers of tubes are used. Of the various anaerobic techniques available, the McIntosh \& Fildes anaerobic jar, with an atmosphere of hydrogen containing $5 \%$ carbon dioxide, was found to be the most satisfactory and efficient for general use. In order to prevent poisoning of the palladium catalyst by hydrogen sulphide, it is necessary to place a dried pad of absorbent cotton-wool impregnated with lead acetate between the cultures and the catalyst.

\section{Crude cultures}

Sources. The sources investigated were: all kinds of soils; river, sea, pond and tap waters; water from gas-holders and oil-storage tanks; oil-well waters; sewage; marine sediments.

Media. For crude and pure cultures we used media based on the following:

Medium $A$ (Baars, 1930): $\mathrm{K}_{2} \mathrm{HPO}_{4}, 0.5$ g.; $\mathrm{NH}_{4} \mathrm{Cl}, 1$ g.; $\mathrm{CaSO}_{4}, 1$ g.; $\mathrm{MgSO}_{4} \cdot 7 \mathrm{H}_{2} \mathrm{O}, 2 \mathrm{~g}$.; sodium lactate $\left(70 \%\right.$ solution), $5 \mathrm{~g} . ; \mathrm{FeSO}_{4} \cdot\left(\mathrm{NH}_{4}\right)_{2} \mathrm{SO}_{4} \cdot 6 \mathrm{H}_{2} \mathrm{O}$, $0.5 \mathrm{~g}$.; tap water, 1 1.; $\mathrm{pH} 7 \cdot 0-7 \cdot 5$, which should be confirmed after sterilization. This medium gives a considerable precipitate on sterilization for 20 min. at $20 \mathrm{lb}$./sq.in. which is no disadvantage in crude cultures, but may be with pure cultures when, for example, growth is determined by turbidity measurements.

Medium $B$ (Starkey, 1938): $\mathrm{K}_{2} \mathrm{HPO}_{4}, 0.5 \mathrm{~g}$.; $\mathrm{NH}_{4} \mathrm{Cl}, 1 \mathrm{~g}$.; $\mathrm{Na}_{2} \mathrm{SO}_{4}, 1$ g.; $\mathrm{CaCl}_{2} \cdot 2 \mathrm{H}_{2} \mathrm{O}, 0 \cdot 1 \mathrm{~g}$.; $\mathrm{MgSO}_{4} \cdot 7 \mathrm{H}_{2} \mathrm{O}, 2 \mathrm{~g}$.; sodium lactate ( $70 \%$ solution), 5 g.; $\mathrm{FeSO}_{4} \cdot\left(\mathrm{NH}_{4}\right)_{2} \mathrm{SO}_{4} \cdot 6 \mathrm{H}_{2} \mathrm{O}, 0 \cdot 5 \mathrm{~g}$.; distilled water, 1 1. (Starkey used tap water); pH 7.0-7.5. This medium gives only a slight precipitate on autoclaving and may be filtered clear without significant loss and resterilized.

It is preferable not to incorporate the ferrous salt in the stock media, but to sterilize a $1 \%$ solution by steaming $1 \mathrm{hr}$. on 3 successive days, and to add $5 \mathrm{ml}$. supernatant liquid to each $100 \mathrm{ml}$. medium immediately before use. Media $\mathbf{A}$ and $\mathbf{B}$ are suitable for growing obligate and facultative non-halophilic strains in crude cultures. For halophilic strains $1-3 \% \mathrm{NaCl}$ is added or tap or distilled water replaced by sea water. Other saline media are described by Rittenberg (1941) and ZoBell (1947).

Addition of sulphite. A varied microflora can be observed when soils are incubated anaerobically at $30^{\circ}$ in media $\mathbf{A}$ and $\mathbf{B}$, but comparatively few characteristic sulphate-reducing vibrios can be seen. Contaminations are very 
persistent and cannot be eliminated by repeated transfers to fresh medium. Baars (1930) considerably diminished the number of contaminating organisms by adding $4 \mathrm{ml}$. of $0.1 \mathrm{~N}-\mathrm{H}_{2} \mathrm{~S}$ to $60 \mathrm{ml}$. medium, but Starkey (1938) did not find this method useful for isolation purposes.

We examined the effect of adding various concentrations of $\mathrm{Na}_{2} \mathrm{SO}_{3} \cdot 7 \mathrm{H}_{2} \mathrm{O}$ to medium $A$ on the microflora of crude cultures from soils incubated at $30^{\circ}$. The effect varied with different soils, but in general the development of sulphatereducers was not appreciably inhibited by concentrations up to $5 \%$, while very considerable purification took place. With some soils almost pure cultures were immediately obtained, and subsequent isolation of pure strains was comparatively easy.

Clearly no obligate non-halophilic sulphate-reducer can develop in the sulphite medium, and if such a strain is desired the sulphite-free medium must be used. It is now our practice, when making crude cultures at $30^{\circ}$ for the isolation of pure cultures, to incubate the inoculum in medium $\mathbf{A}$ with and without $3 \% \mathrm{Na}_{2} \mathrm{SO}_{3} .7 \mathrm{H}_{2} \mathrm{O}$. Most soils yield crude cultures in both media. When, as sometimes occurs, growth in the sulphite medium is inhibited or very slight, subculture from the normal into sulphite medium will usually give rapid sulphate reduction and a simpler microflora. Crude cultures at $55^{\circ}$ have a much simpler microflora and the addition of sulphite is unnecessary.

Sulphite solutions are unstable and sulphite media should be made up shortly before use. A freshly made strong solution (20-30\%) is sterilized by passing through a bacteriological filter and is added in appropriate quantity to sterile medium. For crude cultures solid sulphite may be dissolved in sterile medium immediately before use. The addition of $3 \%$ of sulphite raises the $\mathrm{pH}$ of medium $\mathrm{A}$ from $\mathbf{7 \cdot 2}$ to $c .8 \cdot 4$. It is advisable to adjust to $\mathrm{pH} \mathbf{7 \cdot 2}$ by the addition of about $2 \mathrm{ml} . \mathrm{N}-\mathrm{HCl} / \mathbf{1 0 0} \mathrm{ml}$. medium. Sulphite in concentrations of $2-5 \%$ causes a remarkable lengthening of the bacterial cell in sulphatereducers, varying considerably with the individual strain. This effect will be more fully described in a future communication.

Procedure. The procedure is determined by the source of the inoculum and the type of strain required. Strains from a saline environment are best isolated on medium $\mathrm{A}$ or $\mathrm{B}$ with the addition of $2-3 \% \mathrm{NaCl}$, though many halophilic strains can reduce sulphate in its absence. Most soils and sewages readily yield flourishing crude cultures of sulphate-reducers when 1-2 g. are incubated anaerobically with media $A$ and $B$, with and without $3 \% \mathrm{Na}_{2} \mathrm{SO}_{3} .7 \mathrm{H}_{2} \mathrm{O}$. For these cultures it is convenient to employ stoppered bottles containing $30-50 \mathrm{ml}$., but cultivation in ordinary culture test-tubes in anaerobic jars is equally effective. Waters, on the other hand, vary enormously in the volume necessary to yield positive cultures. With a heavily contaminated soil water we have obtained sulphate reduction from inocula of $0.00001 \mathrm{ml}$; with other waters 50 or $100 \mathrm{ml}$. must be incubated with the medium. Hence, with waters obviously heavily infected, e.g. smelling of $\mathrm{H}_{2} \mathrm{~S}$ and showing vibrios under the microscope, only 1-2 ml. need be used, but normally our practice with waters is to incubate $1,10,50$ and $100 \mathrm{ml}$. samples. Bunker (unpublished observation) grew a strain from $25 \mathrm{ml}$. tap water. For the larger quantities we use stoppered bottles 
of appropriate size or flasks containing alkaline pyrogallol plugs. To prevent undue dilution by the larger inocula, stronger media are used.

When considerable blackening of the medium has occurred, which may take 2-3 days, and sometimes a month, the culture is examined for vibrios. If vibrios predominate, which occurs sometimes in sulphite but rarely in non-sulphite medium, the culture is ready for the isolation of pure strains. If not, transfers are made into fresh medium, preferably using portions of the black sludge, which usually contains a greater concentration of vibrios than the supernatant liquid. Subculturing is continued until microscopical examination reveals a flourishing culture of vibrios; usually three or four transfers are necessary in the absence of sulphite.

Temperature of incubation. The temperature of incubation need not necessarily be near the normal environmental temperature in nature: the first thermophilic sulphate-reducer was obtained from mud in a frozen ditch (Elion, 1925). Crude cultures may be obtained over a very wide range of temperature. Most soils give positive results at $30^{\circ}$ and $55^{\circ}$. Twelve different types of soil from various parts of Greater London all yielded flourishing cultures of sulphatereducers when incubated with medium $\mathbf{A}$ at both temperatures; similar results have been obtained with soils from many different parts of the world.

The development of crude cultures at temperatures between 30 and $55^{\circ}$ has been examined. Portions (1-2 g.) of a Teddington garden soil and of a Syrian soil were incubated anaerobically with medium $A$ at $30,35,40,45,50$ and $55^{\circ}$. All cultures showed considerable sulphate reduction and developed flourishing growths of sulphate-reducers. Other soils similarly incubated gave negative results initially at one or two intermediate temperatures, but on prolonged incubation all gave positive results.

It is difficult to explain these results. No pure strain known to us is capable of developing at all these temperatures without gradual acclimatization. It is most unlikely that more than one or two different species are present in the same sample of soil. More probably there are different strains of the same species adapted to various restricted ranges of temperature, but we have no explanation of how the adaptation has occurred.

\section{Isolation of pure strains from crude cultures}

Starkey (1938) described the fortuitous isolation of pure cultures by incubating at $30^{\circ}$ for 443 days without subcultivation; presumably all contaminating organisms had been destroyed by the prolonged action of hydrogen sulphide. Rittenberg (1941) did not obtain complete purification of crude cultures by storing for 29 months, though partial purification can undoubtedly be effected in this manner. We have used the method of preparing deep agar ('shake') and plate cultures of various dilutions of the crude culture in $0.85 \%$ saline, using medium $\mathrm{B}$ with $2 \%$ agar, filtered clear. With $3 \% \mathrm{Na}_{2} \mathrm{SO}_{3} \cdot 7 \mathrm{H}_{2} \mathrm{O}$ the medium gives more rapid isolation, but in the few instances where growth is inhibited, the medium without sulphite is used.

Nine ml. of cooled but still liquid agar medium are mixed with $1 \mathrm{ml} .30 \%$ 
sulphite (sterilized by filtration), $0.2 \mathrm{ml} . \mathrm{N}-\mathrm{HCl}$ (to bring to $c . \mathrm{pH} 7$ ) and then $1 \mathrm{ml}$. culture dilution, in that order. It is unnecessary to take special anaerobic precautions with the deep agar tubes, as sulphate-reducers grow in all but the upper $\frac{1}{4}$ in. of the medium. Plates are incubated in McIntosh \& Fildes jars; special care should be taken to exhaust the jars thoroughly before admitting the gas mixture. The cultures are incubated at the required temperature until black colonies appear. Both tubes and plates are seeded because growth on solid media is haphazard, and discrete colonies are better obtained sometimes in tubes, sometimes on plates. Colonies which under low power of the microscope appear to be free from neighbouring contaminating colonies are transferred to tubed liquid medium, with and without sulphite, and incubated anaerobically. Stoppered bottles should not be used, for the reasons already given. Starkey (1938) found that the colonies frequently failed to grow when transferred direct into liquid. We have had comparatively few failures by using either medium A or B containing $0 \cdot 1 \%$ Difco yeast extract, which greatly stimulates growth.

Cultures so obtained are rarely pure except in media containing sulphite, and then not always. When contaminations are found, further dilutions must be made either from the liquid culture or from another colony and fresh deep agar and plate cultures made. The process is repeated until the culture is pure. Owing to the heteromorphic character of sulphate-reducers, microscopical examination is not infallible and confirmation of absence of contamination should be made by plating on various media (nutrient agar, glucose agar, etc.) incubated aerobically and anaerobically. The isolation of pure thermophilic strains is usually rapidly accomplished without the addition of sulphite to the medium. H. J. Bunker \& A. C. Thaysen (unpublished observation) isolated a pure strain by means of a micromanipulator. This technique is undoubtedly superior to any other but the apparatus is not generally available.

\section{Stock cultures}

Pure cultures of sulphate-reducing bacteria may be kept alive on artificial media for long periods. Liquid mesophilic cultures in medium A stored at room temperature for a year grew vigorously on subculture. Slope cultures on solid medium (medium $\mathbf{A}+\mathbf{0} \cdot 1 \%$ Difco yeast extract $+2 \%$ agar) in stoppered tubes containing alkaline pyrogallol plugs grew well after 13 months' storage. Thermophilic spore-forming strains, kept at $55^{\circ}$, were viable after 18 months in liquid medium (medium $\mathbf{A}$ ) and after 2 years in agar stabs (medium $\mathbf{A}+2 \%$ agar). Starkey (1938) quotes other examples of longevity. There is, therefore, no difficulty in keeping stock cultures on artificial media both liquid and solid. For preserving the original characteristics of different strains, however, prolonged cultivation on such media is open to grave objection, and sterile clay and sand were tested as media for stock cultures. $\bullet$

Tubes containing $5 \mathrm{~g}$. each, some of moist clay, others of sand, were sterilized by autoclaving for $2 \mathrm{hr}$. at $15 \mathrm{lb}$./sq.in. Stock cultures of four pure strains were prepared by adding 5 drops of actively growing cultures. The tubes were then 
plugged with cotton-wool saturated with alkaline pyrogallol, sealed with a rubber bung and stored at room temperature. After 4 months all four strains on clay grew vigorously when transferred to medium $\mathbf{A}$; no growth was obtained with the sand cultures. After 9 months all four clay cultures were still viable, but three failed to develop after 12 months, and the fourth after 18 months. It is advisable, therefore, to make fresh clay cultures after $c .9$ months.

\section{HETEROTROPHIC GROWTH}

Liquid media. For crude cultures and isolation of pure strains the medium is deliberately kept simple and free from stimulants which will also favour the development of other organisms. Although there is little difficulty in obtaining growth of pure cultures in media $\mathbf{A}$ and $\mathbf{B}$, the amount of cell material is relatively slight, despite the impression of good growth given by precipitation of ferrous sulphide. The latter, which appears as a bulky black precipitate in the cultures, though convenient for demonstrating sulphate reduction, is inconvenient in biochemical and other investigations. Early in our work, we were confronted with the problem of obtaining large quantities of cells free from sulphide and other contaminating material. For this purpose we needed a clear medium giving vigorous growth but containing ferrous iron below the saturation concentration for ferrous sulphide. Bunker (1939) found that yeast, yeast water and filtered yeast culture stimulated growth. This suggested the addition of yeast extract. Eventually, the following medium was found to give consistently rapid and abundant growth, considerable turbidity being obtained within $48 \mathrm{hr}$. with both mesophilic and thermophilic cultures.

Medium C. $\mathrm{K}_{2} \mathrm{HPO}_{4}, 0.5$ g.; $\mathrm{NH}_{4} \mathrm{Cl}, 1$ g.; $\mathrm{Na}_{2} \mathrm{SO}_{4}, 1$ g.; $\mathrm{CaCl}_{2} .6 \mathrm{H}_{2} \mathrm{O}, 0 \cdot 1$ g.; $\mathrm{MgSO}_{4} .7 \mathrm{H}_{2} \mathrm{O}, 2 \mathrm{~g}$.; sodium lactate (70\% solution), $3.5 \mathrm{~g}$.; Difco yeast extract, $1 \mathrm{~g}$.; $\mathrm{FeSO}_{4} \cdot 7 \mathrm{H}_{2} \mathrm{O}, 0.002 \mathrm{~g}$; ; distilled water, 1 l.; bring to $\mathrm{pH} \mathrm{7.5.} \mathrm{Autoclave}$ for $20 \mathrm{~min}$. at $20 \mathrm{lb}$./sq.in. This gives a slight precipitate, but a stable clear solution is obtained by filtering and resterilizing.

Iron requirements. The following experiments show that iron is essential for growth, but only in small quantity.

Medium C, made up with no added ferrous salt, was rendered 'biologically free' of iron by the method of Waring \& Werkman (1943), in which iron complexes formed by the addition of 8 -hydroxyquinoline are removed by chloroform extraction. The iron-free medium was placed in test-tubes which had been cleaned with chromic + sulphuric acid, well washed in distilled water and finally rinsed in conductivity water. A culture in medium $\mathrm{C}$, containing no added ferrous salt, was incubated for 3 days at $30^{\circ}$, centrifuged, the cells washed with the same medium, and inoculated into the iron-free medium. No growth was obtained, though normal growth occurred on addition of $0.0002 \%$ $\mathrm{FeSO}_{4} \cdot 7 \mathrm{H}_{2} \mathrm{O}$.

Good growth was also obtained in six successive subcultures into medium $\mathrm{C}$ made up without added ferrous salt and using A.R. grade materials (except the $\mathrm{K}_{2} \mathrm{HPO}_{4}$ and sodium lactate) and conductivity water in carefully cleaned glassware. Traces of iron present as impurities in the materials used were thus 
sufficient for normal growth. Although no quantitative determinations of the iron contents of the individual constituents were made, qualitative experiments with 8-hydroxyquinoline showed that sodium lactate was the chief source of iron.

Solid media. Growth on the surface of solid media is neither so successful nor so rapid and abundant as in liquid media. It is somewhat capricious; very occasionally luxuriant growth was obtained, and there were fairly frequent unexplained failures. The appearance of abundant growth is often given by intense blackening of media to which ferrous iron has been added, but the quantity of cell material is frequently scanty. The best results were obtained by using a massive inoculum from a vigorous young liquid culture. Media $\mathrm{A}$ and $\mathrm{B}$ with $2 \%$ agar and $1 \%$ Difco yeast extract usually gave satisfactory growth, but the peptone-dextrose agar (peptone, $5 \mathrm{~g}$.; dextrose, 10 g.; $\mathrm{MgSO}_{4} .7 \mathrm{H}_{2} \mathrm{O}, 1.5 \mathrm{~g}$.; $\mathrm{Na}_{2} \mathrm{SO}_{4}, 1.5 \mathrm{~g}$.; $\mathrm{FeSO}_{4}$. $\left(\mathrm{NH}_{4}\right)_{2} \mathrm{SO}_{4} .6 \mathrm{H}_{2} \mathrm{O}, 0 \cdot 1 \mathrm{~g}$.; agar, $20 \mathrm{~g}$.; tap water, 1 l.) of Starkey (1938) gave consistently better results. Attempts were made to grow large quantities of cells free from sulphide on the various solid media containing no added ferrous salt, but were not successful.

\section{AUTOTROPHIC GROWTH}

Pont (1939) claimed to have grown sulphate-reducers in a mineral medium containing steel wool. It is possible, as Hadley (1943) suggests, that organic material was present as vegetable oil on the steel or may have been introduced with the inoculum, and though apparently no carbon source was added, there was probably dissolved carbon dioxide in the medium. Hadley was unable to confirm Pont's results. Czurda (1940) also claimed to have grown sulphatereducers in a mineral medium in the absence of hydrogen; his cultures were admittedly impure, and ZoBell (1946b) suggested that the organisms were using the paraffin wax employed to exclude oxygen from the cultures. van Niel (1943) wrote that 'decisive experiments to show development of the sulphatereducing bacteria in mineral media, on the basis of oxidation of hydrogen with sulphate, have not yet been carried out'.

Starkey \& Wight (1945) were the first to produce substantial evidence that sulphate-reducers are facultative autotrophs. They were able to show that enriched and partly purified cultures grew in an inorganic medium in the presence of hydrogen; the sole carbon source was bicarbonate, and sulphate was reduced to sulphide. They suggested that the necessary energy was obtained by the oxidation of hydrogen. Starkey \& Wight stated, however, that "the results are not entirely satisfactory in that it has not been shown conclusively that pure cultures of the sulphate-reducing bacteria can bring about these reactions'. It had previously been shown by Stephenson \& Stickland (1931) that resting non-proliferating cells of a strain of sulphate-reducers isolated by them contained a hydrogenase, but there was no indication that growth was possible by virtue of this reaction.

As briefly reported (Butlin \& Adams, 1947) we grew one thermophilic and four mesophilic strains through many subcultures in a strictly mineral 
medium in an atmosphere of hydrogen containing $5 \%$ carbon dioxide; no growth took place when hydrogen was excluded. Growth also occurred when sulphate in the medium was replaced by sulphite, thiosulphate and elementary sulphur. Furthermore, the gaseous hydrogen need not be provided as such; it could be produced in the medium by immersing metallic iron in the mineral salt solution. Our experiments with pure cultures show that growth and sulphate reduction occur when rods of mild steel are placed in the inoculated mineral salt medium and incubated anaerobically with no added hydrogen. The cultures remained pure throughout the experiments. Very stringent precautions were taken to exclude all traces of organic material.

\section{Experimental}

Medium D. $\mathrm{K}_{2} \mathrm{HPO}_{4}, 1$ g.; $\mathrm{NH}_{4} \mathrm{Cl}$ (A.R.), 1 g.; $\mathrm{CaSO}_{4}, 1$ g.; $\mathrm{MgSO}_{4} .7 \mathrm{H}_{2} \mathrm{O}$ (A.R.), 2 g.; $\mathrm{NaHCO}_{3}$ (A.R.), 1 g.; conductivity water, 1 l. The $\mathrm{NaHCO}_{3}$ is added separately after sterilization by filtration of $10 \%$ solution $(10 \mathrm{ml}$. to $1 \mathrm{l}$.). pH 7.0-7.5. $1 \%$ solution $\mathrm{FeSO}_{4} \cdot\left(\mathrm{NH}_{4}\right)_{2} \mathrm{SO}_{4} \cdot 6 \mathrm{H}_{2} \mathrm{O}$ (A.R.) sterilized by $1 \mathrm{hr}$. steaming on 3 successive days; $5 \mathrm{ml}$. supernatant liquid added to each $100 \mathrm{ml}$. medium immediately before use.

Glassware. All glassware used in preparation of media and for culture tubes was cleaned in chromic acid, washed in distilled water and finally rinsed in conductivity water. Cotton-wool plugs normally used in culture tubes and flasks containing medium were replaced by loosely-fitting beakers or tubes cleaned in chromic acid, etc. Pipettes were plugged with acid-washed glass wool, placed inside large glass tubes and autoclaved.

Incubation was in McIntosh \& Fildes anaerobic jars containing atmosphere of hydrogen with $5 \% \mathrm{CO}_{2}$; mesophilic strains incubated at $30^{\circ}$, thermophilic at $55^{\circ}$. Cultures of five strains, one thermophilic and four mesophilic, growing in medium $\mathbf{A}$ were first cultivated in medium $\mathbf{D}$ (made with distilled water and contained in tubes plugged with cotton-wool) without taking the elaborate precautions described above. A period of about 8 days elapsed before blackening occurred, showing reduction of sulphate to sulphide. The cultures were taken through several subcultivations. The rate of growth increased considerably, and by the third or fourth subculture reasonably good growth was obtained in 2-3 days. After six subcultivations, when there could have been only very slight traces of organic material present, a change was made to the all-glass culture tubes and to the special precautions for preparing media, etc., described above. Growth persisted through at least six subcultures and showed no signs of failing. Throughout the experimental period, the purity of the cultures was proved microscopically and by seeding on nutrient agar and glucose broth and in broth and glucose broth, aerobically and anaerobically. No growth could be obtained from similar cultures incubated in anaerobic jars containing no hydrogen and from which oxygen was removed by alkaline pyrogallol.

All five strains (four mesophilic, one thermophilic) must therefore be regarded as facultative autotrophs. It should be emphasized that growth is not nearly 
so abundant as in heterotrophic conditions, and for this reason it has not yet been found possible to demonstrate the presence of a hydrogenase in washed suspensions of cells grown autotrophically. However, experiments in Warburg manometers with washed suspensions of the mesophilic strains grown heterotrophically show that hydrogen is absorbed in the presence of sulphate, with formation of sulphide. The presence of a hydrogenase in the autotrophic strains may reasonably be presumed.

\section{Sulphite, thiosulphate and elementary sulphur as hydrogen acceptors}

In heterotrophic growth of sulphate-reducers, sulphite, thiosulphate and elementary sulphur can be substituted for sulphate in the medium, reduction to sulphide taking place in each case (Baars, 1930). Experiments were made to determine whether similar substitutions could be made in media supporting strictly autotrophic growth.

The following basal medium containing no sulphate was made up: $\mathrm{K}_{2} \mathbf{H P O}_{4}$, 1 g.; $\mathrm{NH}_{4} \mathrm{Cl}$ (A.R.), 1 g.; $\mathrm{CaCl}_{2} 6 \mathrm{H}_{2} \mathrm{O}$ (A.R.), $0 \cdot 1$ g.; $\mathrm{MgCl}_{2} \cdot 6 \mathrm{H}_{2} \mathrm{O}$ (A.R.), $1 \cdot 1$ g.; $\mathrm{NaHCO}_{3}$ (A.R.), 1 g., added separately after sterilization of $10 \%$ solution by filtration; conductivity water, 11 . pH adjusted to 7.0-7.5 after addition of bicarbonate. $\mathrm{FeCl}_{2}$ was used instead of $\mathrm{FeSO}_{4} \cdot\left(\mathrm{NH}_{4}\right)_{2} \mathrm{SO}_{4} \cdot 6 \mathrm{H}_{2} \mathrm{O}$ as indicator. A $2 \% \mathrm{FeCl}_{2}$ solution was boiled for $5 \mathrm{~min}$. and 1 drop added to each $10 \mathrm{ml}$. medium before use.

Sulphite medium was prepared by adding $20 \mathrm{ml}$. of $20 \% \mathrm{Na}_{2} \mathrm{SO}_{3} .7 \mathrm{H}_{2} \mathrm{O}$ (sterilized by filtration) to each litre of basal medium. Owing to the instability of sulphite solutions, filtration and addition to medium was performed rapidly and immediately before inoculation. Thiosulphate medium was prepared by adding 4 g. $\mathrm{Na}_{2} \mathrm{~S}_{2} \mathrm{O}_{3} .5 \mathrm{H}_{2} \mathrm{O}$ (A.R.)/l. to the basal medium; sulphur medium by adding $c .0 \cdot 1 \mathrm{~g}$. precipitated sulphur to each $10 \mathrm{ml}$. basal medium in culture tubes and sterilizing by steaming on 3 successive days before addition of bicarbonate. The cultures were incubated in an atmosphere of $\mathbf{H}_{2}$ containing $5 \% \mathrm{CO}_{2}$.

The technique used was similar to that already described for autotrophic growth with sulphate as hydrogen acceptor, preliminary experiments being performed in culture tubes plugged with cotton-wool and the final subcultures carried out in all-glass culture tubes, with stringent precautions to eliminate extraneous organic material. Reasonably good growth with reduction to sulphide was obtained with four mesophilic strains at $30^{\circ}$ and one thermophilic strain at $55^{\circ}$, except in the medium containing elementary sulphur, which showed definite blackening but very scanty growth. Uninoculated controls remained unchanged.

\section{Autotrophic growth in presence of metallic iron}

Starkey \& Wight (1945) grew sulphate-reducing bacteria at $28^{\circ}$ in mineral medium to which steel-wool had been added. Hydrogen is evolved through reaction with water when iron is immersed in the culture medium. As with the cultures growing autotrophically in an atmosphere of $\mathrm{H}_{2}$ it was assumed that 
the energy for growth was obtained by the oxidation of hydrogen and that sulphate acted as hydrogen acceptor. Starkey \& Wight stated that their technique was not well adapted to pure culture work, and contaminants were present in all cultures at the end of the incubation period. In our experiments using metallic iron as the source of hydrogen, we used the technique already described for autotrophic growth, and our cultures remained pure.

Steel rods about $1 \mathrm{in}$. long were first cleaned by three immersions in pure benzene, then washed with hot distilled water, rinsed in conductivity water and finally sterilized by autoclaving in medium $\mathbf{D}$ before addition of bicarbonate. After inoculation with two drops of culture grown through several subcultures in mineral medium contained in all-glass culture tubes, the cultures were incubated in an anaerobic jar containing alkaline pyrogallol. Four mesophilic cultures were placed at $30^{\circ}$ and one thermophilic culture at $55^{\circ}$. After 2-3 days a black precipitate began to appear on the surface of the steel rod and growth, though scanty, was definite and persisted through several subcultures. Uninoculated controls remained unchanged.

\section{DISCUSSION}

No attempt has been made to elucidate the autotrophic metabolism of the strains investigated, but in view of the fact that hydrogen is essential and that the corresponding heterotrophic mesophilic strains contain a hydrogenase, it may reasonably be inferred that the oxidation of hydrogen by the hydrogenase system is the source of energy. The energy released must be used to fix $\mathrm{CO}_{2}$ for growth purposes and also to supply the energy for the reduction of sulphate (or sulphite, thiosuiphate and sulphur) to sulphide, a reaction which appears to be essential to the life of the cell.

Some problems of considerable biochemical interest are raised, in particular the mechanism which must link the energy-releasing and energy-absorbing systems. The reduction of sulphate to sulphide by stages suggested by Kluyver (1931), but not yet experimentally established, is presumably linked to the oxidation of hydrogen by hydrogenase, but there remains the problem of synthesis of cell materials from bicarbonate as sole carbon source. LePage \& Umbreit (1943) showed that when the aerobic obligate autotroph Thiobacillus thiooxidans oxidizes sulphur to sulphuric acid, an energy-rich adenosine-3-triphosphate is formed, and that energy obtained from the energy-rich phosphate bonds may be used for growth purposes. The possibility that a similar mechanism operates in the autotrophic metabolism of sulphatereducers might be explored.

Another matter for speculation is the manner whereby elementary sulphur, which is insoluble in the growth medium, is reduced to sulphide during heterotrophic or autotrophic growth of sulphate-reducers in apparent violation of the principle that energy transformations take place at the surface of, or within the cell. It has been suggested that cells of $T h$. thiooxidans contain unsaturatedfat globules which dissolve sulphur by direct contact and so bring it into the 
cell for oxidation (Umbreit, Vogel \& Vogler, 1942), though this speculation has been partially disputed by Knaysi (1943).

The utilization of the hydrogen evolved when metallic iron is immersed in mineral medium provides additional evidence for the presumed role of sulphatereducers in anaerobic corrosion of ferrous pipes, namely, that of depolarizing the cathodic elements of electro-chemical systems on the surface of the metal. It by no means follows that the organisms taking part in the corrosion process are living autotrophically, for corrosion of this type is usually more severe in the presence of the products of cellulose decomposition, which provide oxidizable food material for the organisms. It is probable, therefore, that future investigations will show that a hydrogenase plays an important part in the heterotrophic as well as the autotrophic metabolism of sulphate-reducers. It is improbable that all sulphate-reducers are capable of autotrophic growth for Stephenson (1947) states that a hydrogenase is not invariably found in this group. The possession or non-possession of a hydrogenase might serve as a basis for differentiation into separate species.

We are deeply indebted to Mr H. J. Bunker, both for his past work in the same field at this Laboratory and for his valuable criticisms and suggestions while reading through the manuscript. This paper is published by permission of the Director of the Chemical Research Laboratory.

\section{REFERENCES}

BaArs, J. K. (1930). Over Sulfaatreductie door Bacteriën. Dissertation, W. D. Meinema, N. V., Delft.

BeiJerinck, W. M. (1895). Über Spirillum desulfuricans als Ursache von Sulfatreduktion. Zbl. Bakt. (2. Abt.), 1, 1, 49, 104.

Bergey (1939). Manual of Determinative Bacteriology (ed. D. H. Bergey, R. S. Breed, E. G. D. Murray \& A. P. Hitchens), 5th ed. Baltimore: Williams and Wilkins.

Bergey (1948). Manual of Determinative Bacteriology (ed. R. S. Breed, E. G. D. Murray \& A. P. Hitchens), 6th ed. Baltimore: Williams and Wilkins.

Bunker, H. J. (1936). A Review of the Physiology and Biochemistry of the Sulphur Bacteria. Dep. Sci. Industr. Res., Chem. Res. Special Rep. no. 3. London: H.M. Stat. Office.

Bunker, H. J. (1938). Microbiological experiments in anaerobic corrosion. J. Soc. chem. Ind., Lond., 58, 93.

BUNKER, H. J. (1939). Factors influencing the growth of Vibrio desulphuricans. Abstr. Comm. 3rd Int. Congr. Microbiol. p. 64.

Butlin, K. R. \& Adams, M. E. (1947). Autotrophic growth of sulphate-reducing bacteria. Nature, Lond., $160,154$.

Copenhagen, W. J. (1934). Occurrence of Sulphides in Certain Areas of the Sea Bottom on the South African Coast. Union S. Afr. Dep. Comm. and Ind., Fish and Marine Biol. Survey Div., Investigational Report no. 3.

Czurda, V. (1940). Zur Kenntnis der bakteriellen Sulfat-reduktion. Arch. Mikrobiol. $11,187$.

Datra, S. C. (1943). Production of elementary sulphur by reduction of sulphate through bacterial agency. Curr. Sci. 12, 305.

Delden, A. van (1903). Beitrag zur Kenntnis der Sulfat-reduktion durch Bakterien. Zbl. Bakt. (2. Abt.), 11, 31, 113.

Elion, L. (1925). A thermophilic sulphate-reducing bacterium. Zbl. Bakt. (2. Abt.), $63,58$. 
GaHL, R. \& ANDERson, B. (1928). Sulphate-reducing bacteria in California oil waters. Zbl. Bakt. (2. Abt.), 73, 331.

HADLEy, R. F. (1943). The Influence of Sporovibrio desulphuricans on the Current and Potential Behaviour of Corroding Iron. Philadelphia: Susquehanna Pipe Line Company.

KLIGLER, I. J. \& Guggenheim, K. (1938). The influence of vitamin C on the growth of anaerobes in the presence of air. J. Bact. 35, 141.

Kruyver, A. J. (1931). The Chemical Activities of Micro-organisms. London: University of London Press.

Kluyver, A. J. \& van Niel, C. B. (1936). Prospects for a natural system of classification of bacteria. Zbl. Bakt. (2. Abt.), 94, 369.

KNAYSI, G. (1943). A cytological and microchemical study of Thiobacillus thiooxidans. J. Bact. 46, 451.

Kühr, C. A. H. von Wolzogen \& van Der Vlugt, I. S. (1934). The graphitization of cast iron as an electrobiochemical process in anaerobic soils. Water, 18, 147.

LePage, G. A. \& Umbreit, W. W. (1943). The occurrence of adenosine-3-triphosphate in autotrophic bacteria. J. biol. Chem. 148, 255.

Niel, C. B. van (1943). Biochemical problems of the chemoautotrophic bacteria. Physiol. Rev. 23, 338.

Pon'r, E. G. (1939). Association of sulphate reduction in the soil with anaerobic iron corrosion. J. Aust. Inst. agric. Sci. 5, 170.

Rittenberg, S. C. (1941). Studies on marine sulfate-reducing bacteria. Thesis, Univ. California.

Starkey, R. L. (1938). A study of spore formation and other morphological characteristics of Vibrio desulphuricans. Arch. Mikrobiol. 9, 268.

Starkey, R. L. \& Wight, K. M. (1945). Anaerobic Corrosion of Iron in Soil. Final report of the American Gas Ass. Iron Corrosion Res. Fellowship, Amer. Gas Ass. New York.

Stephenson, M. (1947). Some aspects of hydrogen transfer. Ant. van Leeurvenhoek. $12,31$.

Stephenson, M. \& Stickland, L. (1931). The reduction of sulphate to sulphide by molecular hydrogen. Biochem. J. 25, 215.

Tanner, F. W. (1918). Studies on the bacterial metabolism of sulphur. II. Formation of hydrogen sulphide from certain sulphur compounds by yeast-like fungi. J. Amer. chem. Soc. 40, 663 .

Tausson, W. A. \& Alioschina, W. A. (1932). Uber die Bakterielle Sulfatreduktion bei Anwesenheit der Kohlenwasserstoffe. Mikrobiology (U.S.S.R.), 1, 229.

Umbreit, W. W., Vogel, H. R. \& Vogler, K. G. (1942). The significance of fat in sulphur oxidation by Thiobacillus thiooxidans. J. Bact. 43, 141.

Waring, W. S. \& Werkman, C. H. (1943). Growth of bacteria in an iron-free medium. Arch. Biochem. $1,303$.

ZoBels, C. E. (1945). The role of bacteria in the formation and transformation of petroleum hydrocarbons. Science, 102, 364.

ZoBell, C. E. (1946a). Marine Microbiology. Waltham, Mass.: Chronica Botanica Company.

ZoBeis., C. E. (1946b). Action of micro-organisms on hydrocarbons. Bact. Rev. $10,1$.

ZoBeLt, C. E. (1947). Bacterial release of oil from oil-bearing materials. World Oil, 126,$36 ; 127,35$. 